\title{
Global Partial Response in Lymph Nodes
}

National Cancer Institute

\section{Source}

National Cancer Institute. Global Partial Response in Lymph Nodes. NCI Thesaurus. Code C159959.

Cumulative reduction of 50 percent or more of the sum of products of diameter of each abnormal lymph node at baseline and no new lymph node greater than $1.5 \mathrm{~cm}$ in the diameter of the long axis or greater than $1.0 \mathrm{~cm}$ in the diameter of the short axis if the long axis is $1-1.5 \mathrm{~cm}$ diameter. 